\title{
Antecipar a Vida Consulta Pré-concepcional - Caracterização das puérperas do Hospital de Santo André - Leiria
}

Teresa Maria Bacelo,* Maria Soledade Lopes**

\section{RESUMO}

Introdução: A importância dos cuidados pré-concepcionais tem sido cada vez mais enfatizada nos últimos anos, visando a identificação e modificação dos riscos que possam alterar a normal evolução de uma futura gestação.

Objectivos: Caracterizar as puérperas do Hospital de Santo André, internadas no mês de Dezembro de 2007, quanto ao meio sócio-demográfico, estilos de vida e gravidez; identificar as puérperas que realizaram consulta pré-concepcional e caracterizar a consulta pré-concepcional efectuada.

Metodologia: Tipo de estudo - Estudo observacional e descritivo; Local - Serviço de Obstetrícia do Hospital de Santo André Leiria; População em estudo - Puérperas internadas durante o mês de Dezembro de 2007 no Serviço de Obstetrícia do Hospital de Santo André - Leiria; Métodos: Foi aplicado um questionário anónimo, pré-testado, abordando variáveis respeitantes à caracterização sócio-demográfica, gravidez, parto, hábitos, estilos de vida e consulta pré-concepcional. Foram excluídas mulheres analfabetas, que não soubessem ler/falar português e as que não aceitassem participar no estudo. Definiu-se consulta pré-concepcional como qualquer consulta realizada antes de engravidar, com o objectivo de saber se estava tudo bem com a mulher. Resultados: Foram estudadas 122 mulheres. O grupo etário predominante foi o dos 30 aos 34 anos. A prevalência de mulheres que tiveram consulta pré-concepcional foi de 49,2\%, sendo que $75 \%$ (45/60) teve consulta no Médico Obstetra particular e apenas 18,3\% (11/60) no Centro de Saúde. As principais razões apontadas para a não realização da consulta foram a existência de uma gravidez não planeada (18/60), o desconhecimento das consultas (11/60) e a não importância atribuída a este tipo de consultas (11/60).

Conclusão: É fundamental a divulgação e motivação das mulheres para este tipo de consulta, devendo nós, como Médicos de Família, aproveitar as inúmeras oportunidades que temos para o fazer.

Palavras-chave: Consulta Pré-concepcional; Aconselhamento Pré-concepcional; Cuidados pré-concepcionais.

\section{INTRODUÇÃO}

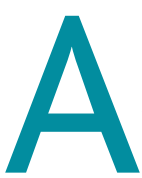

pesar da importância dos cuidados pré-concepcionais ser, actualmente, reconhecida universalmente e de vários autores terem vindo a enfatizar os seus benefícios nos últimos anos, a implementação desta forma de medicina de prevenção não tem sido bem sucedida. ${ }^{1,2}$ Em inúmeros casos, a gravidez não é diagnosticada antes do período crítico da organogénese, e muitas mulheres já terão exposto o feto aos riscos potenciais de substâncias de abuso, medicamentos ou consequências de doenças

*Interna Complementar de Medicina Geral e Familiar, Centro de Saúde da Batalha

**Assistente graduada de Medicina Geral e Familiar, Centro de Saúde da Batalha maternas mal controladas. ${ }^{1-9}$ Por outro lado, mais de 50 por cento das gravidezes não são planeadas, ${ }^{3,4}$ o que pode levar a uma má vigilância pré-natal e à manutenção dos comportamentos de risco.

Por outro lado, tem crescido o reconhecimento dos limites dos cuidados pré-natais e da importância da saúde materna antes da concepção. É deste modo que faz todo o sentido a implementação da consulta pré-concepcional, cujo objectivo é identificar e modificar os riscos biomédicos, comportamentais e sociais que possam alterar a normal evolução de uma futura gestação e, deste modo, contribuir ainda mais para a melhoria dos índices de morbimortalidade materna e infantil. ${ }^{1-9}$ 
Segundo a circular normativa da Direcção-Geral da Saúde No 02/DSMIA de 16/01/06, sobre prestação de cuidados pré-concepcionais, «...o aconselhamento pré-concepcional deve ser entendido como um processo durante o qual o médico deve obter toda a informação possível para estabelecer o risco de anomalia reprodutiva, numa determinada mulher/casal e propôr medidas tendentes a minimizar ou eliminar esse risco. Tem em conta não só factores genéticos, mas também factores que podem ter impacto sobre o feto, como por exemplo, a idade da mulher, hábitos, doenças crónicas maternas, infecções, vários fármacos e poluentes. Proporciona ainda uma excelente oportunidade para discutir assuntos relacionados com os direitos sexuais e reprodutivos e dar algumas informações sobre a fisiologia da reprodução, como por exemplo, o ciclo menstrual, a ovulação, o período fértil e o tempo que poderá ser necessário para engravidar. Permite, também, informar sobre os objectivos da vigilância pré-natal, o seu conteúdo, a sua frequência, de modo a que o casal possa estabelecer expectativas realistas a respeito da gravidez (...). ${ }^{6}$

O acrónimo «VITAL MOM» $»^{1}$ (Quadro I) é uma forma simples de nos relembrar as questões a colocar e as intervenções recomendadas para promover uma gravidez saudável e bem sucedida., ${ }^{3,7}$

\section{OBJECTIVOS}

Objectivo geral: Caracterizar as puérperas do Hospital de Santo André, que estiveram internadas durante o mês de Dezembro de 2007, quanto à realização da consulta pré-concepcional.

Objectivos específicos: Caracterizar: 1) as puérperas quanto ao meio sócio-demográfico e estilos de vida; 2) o tipo de vigilância efectuada durante a gravidez: antecedentes obstétricos, número de consultas e local de vigilância; 3) as puérperas que realizaram consulta pré-concepcional; 4) a consulta pré-concepcional quanto ao pedido de análises, verificação do estado vacinal, aconselhamento efectuado, realização de citologia cervico-vaginal e suplementação com ácido fólico.

\section{METODOLOGIA}

População em estudo: Puérperas internadas no Serviço de Obstetrícia do Hospital de Santo André - Leiria, durante o mês de Dezembro de 2007.

\begin{tabular}{|c|c|}
\hline \multicolumn{2}{|c|}{$\begin{array}{l}\text { QUADRO I. Acrónimo «Vital Mom» para a consulta } \\
\text { pré-concepcional }\end{array}$} \\
\hline $\begin{array}{l}\boldsymbol{V} \text {-Vitamins and } \\
\text { minerals }\end{array}$ & $\begin{array}{l}\text { Suplementação com ácido fólico } \\
\text { Averiguar necessidade de } \\
\text { suplementação com ferro e } \\
\text { vitaminas pré-natais }\end{array}$ \\
\hline I-Immunizations & $\begin{array}{l}\text { Verificar estado vacinal para rubéola, } \\
\text { tétano, varicela, Hepatite B e } \\
\text { completar a vacinação, se necessário }\end{array}$ \\
\hline T-Test & $\begin{array}{l}\text { Citologia cervicovaginal } \\
\text { Serologias para sífilis, Hepatite B, } \\
\text { Toxoplasmose, Rubéola, } \\
\text { Citomegalovírus, Varicela, HPV } \\
\text { Tipo de sangue ABO e Rh } \\
\text { Rastreio de hemoglobinopatias } \\
\text { Teste de tuberculina (especialmente } \\
\text { nas profissões de risco) } \\
\text { Análise de urina }\end{array}$ \\
\hline $\begin{array}{l}\text { A-Ask about } \\
\text { genetic and } \\
\text { obstetric history, } \\
\text { spousal abuse }\end{array}$ & $\begin{array}{l}\text { História genética (baseada na idade } \\
\text { materna, etnia e história familiar) } \\
\text { História obstétrica }\end{array}$ \\
\hline $\begin{array}{l}L \text {-Lose cigarettes, } \\
\text { alcohol and } \\
\text { recreational drugs }\end{array}$ & $\begin{array}{l}\text { Evicção tabágica, de álcool e de drogas } \\
\text { de abuso } \\
\text { Explicar riscos do seu consumo }\end{array}$ \\
\hline $\begin{array}{l}\text { M-Medical } \\
\text { conditions and } \\
\text { medications }\end{array}$ & $\begin{array}{l}\text { Verificar existência de doenças, tais } \\
\text { como diabetes mellitus, hipertensão } \\
\text { arterial e epilepsia, trombose venosa } \\
\text { profunda, depressão ou ansiedade. } \\
\text { Verificar medicação efectuada e se } \\
\text { necessário alterar }\end{array}$ \\
\hline $\begin{array}{l}\text { O-Ocupational } \\
\text { exposures }\end{array}$ & $\begin{array}{l}\text { Verificar a existência de exposição a } \\
\text { substâncias potencialmente } \\
\text { perigosas }\end{array}$ \\
\hline $\begin{array}{l}\text { M-Modify: diet, } \\
\text { exercise, stress, } \\
\text { employment, } \\
\text { caffeine intake }\end{array}$ & $\begin{array}{l}\text { Aconselhamento acerca de } \\
\text { alimentação, exercício físico, } \\
\text { controlo do stress. }\end{array}$ \\
\hline
\end{tabular}

Amostra do estudo: de conveniência, todas as puérperas internadas no Serviço de Obstetrícia do Hospital de Santo André - Leiria, durante o mês de Dezembro de 2007.

Durante o ano de 2007 realizaram-se cerca de 2.400 partos no Hospital de Santo André - Leiria, mas vamos cingir-nos apenas ao estudo do mês de Dezembro. 
Tipo de estudo: Estudo observacional, descritivo e com uma componente analítica.

Variáveis: Neste estudo foram incluídas as seguintes variáveis:

- Sócio-demográficas:

- Idade materna

- Raça

- Estado civil

- Escolaridade

- Situação laboral

- Profissão (escala Graffar)

- Concelho de residência

- Estilo de vida

- Consumo de tabaco

- Consumo de álcool

- Consumo de drogas

- Gravidez:

- Planeada / Desejada

- Método anticoncepcional utilizado

- Paridade

- No de consultas efectuadas

- Local de vigilância

- Início da vigilância

- Consulta pré-concepcional

- Realização da consulta pré-concepcional

- Local da consulta pré-concepcional

- Razões da não realização da consulta pré-concepcional

- Caracterização da consulta pré-concepcional

- Pedido de análises

- Verificação do estado vacinal

- Aconselhamento efectuado

- Realização da citologia cervicovaginal

- Suplementação com ácido fólico

Medições: Foi aplicado um questionário anónimo, pré-testado em cinco puérperas, que não foram incluídas na amostra estudada. O questionário era composto por questões fechadas e abertas, abordando variáveis respeitantes à caracterização sócio-demográfica, gravidez, parto, hábitos, estilos de vida e consulta pré-concepcional.

Os questionários eram entregues pelo autor do estudo às puérperas, todos os dias úteis da semana, de manhã. Eram posteriormente recolhidos após auto-preenchimento até ao momento da alta.

Definiu-se consulta pré-concepcional como qual- quer consulta realizada antes de engravidar, com o objectivo de saber se estava tudo bem com a mulher.

Critérios de inclusão: todas as mulheres que foram internadas por pós-parto no Serviço de Obstetrícia do Hospital de Santo André, durante o mês de Dezembro de 2007.

Critérios de exclusão: mulheres que não aceitassem participar no estudo.

Foi solicitada previamente a autorização formal do Director do Serviço de Obstetrícia do Hospital de Santo André - Leiria.

Os dados obtidos foram codificados e introduzidos numa matriz de dados, sendo depois tratados com o programa informático de estatística SPSS 15,0 for Windows Evaluation Version. Apesar de se tratar de uma amostra de conveniência foi utilizado o teste do chi-quadrado, para a comparação de proporções.

\section{RESULTADOS}

\section{Caracterização sócio-demográfica}

As características sócio-demográficas das puérperas inquiridas estão resumidas na Figura 1 e Quadro II.

Durante o ano de 2007 realizaram-se cerca de 2.400 partos no Hospital de Santo André- Leiria. O estudo incluíu as puérperas que aceitaram participar durante o mês de Dezembro. Foram inquiridas 122 mulheres, com a idade média de 30,1 anos. O grupo etário predominante foi o dos 30 aos 34 anos, havendo duas adolescentes e 18 mulheres com 35 ou mais anos. Quanto ao estado civil, sobressai uma percentagem significativa de mulheres não casadas (33,6 por cento). Relativamente à situação laboral, 22,1 por cento das puérperas encon-

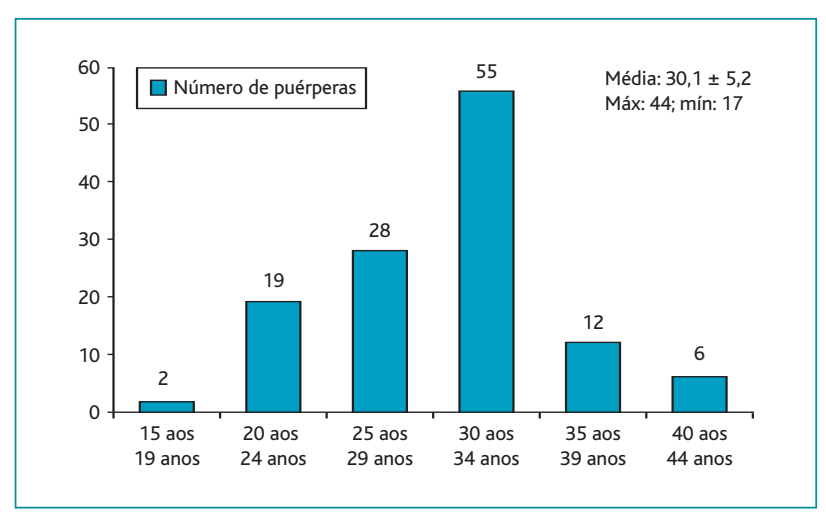

Figura 1. Distribuição das puérperas por grupo etário. 


\begin{tabular}{|c|c|}
\hline \multicolumn{2}{|c|}{$\begin{array}{l}\text { QUADRO II. Características sócio-demográficas } \\
\text { das puérperas }\end{array}$} \\
\hline $\begin{array}{l}\text { Idade Materna } \\
\text { (média } \pm \mathrm{dp}) \text { (anos) }\end{array}$ & $\begin{array}{l}30,1 \pm 5,2 \\
(\max -44: \text { mín }-17)\end{array}$ \\
\hline Raça & $\begin{array}{l}\text { Caucasiana 99,2\% (121/122) } \\
\text { Negra 0,8\% (1/122) }\end{array}$ \\
\hline Estado civil & $\begin{array}{l}\text { Casada } 66,4 \%(81 / 122) \\
\text { Solteira } 17,2 \%(21 / 122) \\
\text { Divorciada 4,9\% (6/122) } \\
\text { União de facto } 11,5 \%(14 / 122)\end{array}$ \\
\hline Escolaridade & $\begin{array}{l}\text { Analfabetismo 1,6\% (2/122) } \\
\text { Básico 19,7\% (24/122) } \\
\text { Secundário 56,6\% (69/122) } \\
\text { Universitário 22,1\% (27/122) }\end{array}$ \\
\hline Situação laboral & $\begin{array}{l}\text { Trabalhadora } 77,1 \%(94 / 122) \\
\text { Desempregada } 22,1 \%(27 / 122) \\
\text { Estudante } 0,8 \%(1 / 122)\end{array}$ \\
\hline Profissão (Escala Graffar) & $\begin{array}{l}1^{\circ} \text { grau } 9,8 \%(12 / 122) \\
2^{\circ} \text { grau } 7,4 \%(9 / 122) \\
3^{\circ} \text { grau } 26,3 \%(32 / 122) \\
4^{\circ} \text { grau } 31,1 \%(38 / 122) \\
5^{\circ} \text { grau } 4,9 \%(6 / 122) \\
\text { Desconhecido/Não aplicável } \\
20,5 \%(25 / 122)\end{array}$ \\
\hline Concelho de residência & $\begin{array}{l}\text { Leiria 40,9\% (50/122) } \\
\text { Alcobaça 4,1\% (5/122) } \\
\text { Batalha 4,1\% (5/122) } \\
\text { Marinha Grande 12,3\% (15/122) } \\
\text { Pombal 2,5\% (3/122) } \\
\text { Ourém 8,2\% (10/122) } \\
\text { Porto de Mós 7,4 \% (9/122) } \\
\text { Torres Novas 7,4 \% (9/122) } \\
\text { Entroncamento 2,5\% (3/122) } \\
\text { Alcanena 5,7\% (7/122) } \\
\text { Figueira da Foz 0,8\% (1/122) } \\
\text { Desconhecido 4,1\% (5/122) }\end{array}$ \\
\hline
\end{tabular}

trava-se desempregada. A maioria das que trabalhavam exercia uma profissão que se enquadrava no grau três ou quatro de Graffar. Cerca de 41 por cento tinha residência no concelho de Leiria.

\section{Caracterização quanto aos estilos de vida}

As características quanto aos estilos de vida estão listadas no Quadro III.

Aproximadamente 18,0 por cento das mulheres in- quiridas eram fumadoras, mantendo este hábito durante a gravidez 86,3 por cento destas. Em relação aos hábitos alcoólicos, 2,5 por cento das mulheres referiram ingestão de bebidas alcoólicas antes da gravidez e 0,8 por cento durante a gravidez. Uma percentagem de 3,3 por cento das mulheres $(4 / 122)$ referiu já ter tido contacto com drogas ilícitas em alguma altura da sua vida, mas nenhuma durante a gravidez.

\section{Caracterização da gravidez}

A caracterização da gravidez resume-se no Quadro IV.

Das 122 mulheres questionadas, 71,3 por cento (87/122) teve uma gravidez planeada, e 88,5 por cento (108/122) tiveram uma gravidez desejada. Aproximadamente 77,9 por cento $(95 / 122)$ utilizavam algum método anticoncepcional anteriormente à gravidez, sendo que a maioria utilizava um anticoncepcional oral - 70,5 por cento (86/122). De referir que 20 por cento não utilizava qualquer anticoncepcional antes da gravidez. $\mathrm{O}$ método anticoncepcional foi suspenso em 90,6 por cento dos casos (87/96) para engravidar. A iniciativa da suspensão do método anticoncepcional partiu, na maioria dos casos, da própria mulher $(60,9$ por cento; 53/87).

Cerca de 37,7 por cento das mulheres (46/122) eram primíparas e 59,0 por cento (72/122) multíparas.

A gestação foi vigiada medicamente, com seis ou mais consultas em 85,2 por cento dos casos (104/122) e destas, quase 15 por cento teve dez ou mais consultas durante a gravidez. O início da vigilância foi no primeiro trimestre da gravidez em 88,5 por cento (108/122), 6 por cento só iniciou a vigilância no segundo e dois por cento no terceiro trimestre. A gravidez foi seguida maioritariamente por obstetra particular em 57,4 por cento $(70 / 122)$, sendo que apenas 16,4 por cento $(20 / 122)$ foi seguida exclusivamente no Centro de Saúde.

\section{Consulta pré-concepcional}

Na presente amostra verificou-se que 49,2 por cento (60/122) das mulheres teve consulta pré-concepcional, tendo sido esta efectuada maioritariamente pelo Obstetra particular em 45 dos 60 casos, e em apenas 11 casos foi efectuada no Centro de Saúde. Das mulheres que não tiveram consulta pré-concepcional, 18 referiram como razão principal o facto de terem tido uma gravi- 
QUADRO III. Estilos de vida antes da concepção e durante a gravidez $(\mathrm{N}=122)$

\begin{tabular}{|c|c|c|c|c|}
\hline \multirow[b]{2}{*}{ Estilos de vida } & \multicolumn{2}{|c|}{ Antes da concepção } & \multicolumn{2}{|c|}{ Durante a gravidez } \\
\hline & $\mathrm{n}$ & $\%$ & $\mathbf{n}$ & $\%$ \\
\hline Consumo & Sim: 22 & 18,0 & Sim: 19 & 15,6 \\
\hline \multirow[t]{2}{*}{ de tabaco } & Não: 96 & 78,7 & Não: 99 & 81,1 \\
\hline & Desconhecido: 4 & 3,3 & Desconhecido: 4 & 3,3 \\
\hline Consumo & Sim: 3 & 2,5 & Sim: 1 & 0,8 \\
\hline \multirow[t]{2}{*}{ de álcool } & Não: 114 & 93,4 & Não: 116 & 95,1 \\
\hline & Desconhecido: 5 & 4,1 & Desconhecido: 5 & 4,1 \\
\hline Consumo & Sim: 4 & 3,3 & Sim: 0 & 0,0 \\
\hline \multirow[t]{2}{*}{ de drogas } & Não: 114 & 93,4 & Não: 118 & 96,7 \\
\hline & Desconhecido: 4 & 3,3 & Desconhecido: 4 & 3,3 \\
\hline
\end{tabular}

lhos pertencentes ao Distrito de Leiria, mas um número significativo pertencia a outros distritos. Teria sido interessante perceber quais as razões que levaram estas mulheres a optar pelo Hospital de Santo André.

Cerca de 20 por cento das puérperas não utilizava qualquer método anticoncepcional antes da gravidez, e das que utilizava, cerca de 10 por cento não o suspendeu. Para além disso, a maioria das mulheres suspendeu o anticoncepcional por iniciativa própria.

Aproximadamente um terço das mulheres não planeou a gravidez e seis por cento não a desejou. Apesar de o número de gra-

dez não planeada, 11 referiram desconhecer estas consultas e 11 não acharam importante a sua realização. (Quadro V)

Em relação ao cumprimento dos protocolos da consulta pré-concepcional, verificou-se que o critério mais cumprido foi o pedido de análises laboratoriais e os menos cumpridos foram o aconselhamento sobre exercício físico e a suplementação com ácido fólico. Quando se procurou verificar se havia correlação entre o local da consulta pré-concepcional e a realização dos protocolos, verificou-se que só havia relação estatisticamente significativa para a suplementação com ácido fólico e o local de realização da consulta pré-concepcional ( $p=0,003$ ) (Quadro VI)

Verificou-se uma relação estatisticamente significativa entre a realização da consulta pré-concepcional e o nível de escolaridade ( $p=0,001$ ), com o estado civil ( $p=0,001)$, e com a profissão, classificada segundo Graffar ( $p=0,004)$, o mesmo não se verificando em relação ao grupo etário ( $p=0,233)$ e o concelho de residência $(p=0,583)$. (Quadro VII)

\section{DISCUSSÃO}

Das 122 mulheres estudadas, duas eram adolescentes e 18 tinham 35 ou mais anos, sendo o grupo etário predominante o dos 30 aos 34 anos.

Apesar de a maioria das mulheres possuir como habilitações literárias o ensino secundário, 26 possuíam apenas o ensino básico e duas eram analfabetas.

A maioria da população inquirida residia em conce- videzes não planeadas ser bastante inferior ao encontrado noutros estudos consultados, que apontam para taxas entre os 40 e os 50 por cento, ${ }^{3,4,8}$ este valor denota ainda um grande caminho a percorrer, passando grande parte pela aposta nos Cuidados de Saúde Primários e na Educação para a Saúde.

No que respeita ao seguimento durante a gravidez, a maioria foi seguida pelo Médico Obstetra, sendo seguidas no Centro de Saúde apenas 16,4 por cento. Os Cuidados de Saúde Primários revelaram, efectivamente, um papel muito pouco activo. Seria interessante estudar os motivos que levam a isto, tentando pesquisar outras variáveis, nomeadamente informação, acessibilidade à consulta, disponibilidade do médico, confiança no seu trabalho, necessidade de alargamento do horário dos centros de saúde, entre outras.

A prevalência da realização da consulta pré-concepcional foi de 49,2 por cento, valor este, contudo, ainda inferior ao objectivo da campanha «Healthy People 2000», cujo valor alvo era de 60 por cento. ${ }^{4}$

Mais uma vez, e tal como para o seguimento da gravidez, a maioria das mulheres optou pelo médico obstetra para a realização da consulta pré-concepcional.

Das mulheres que não tiveram consulta pré-concepcional, 18 das 60 referiram como principal razão o facto de terem tido uma gravidez não planeada, 11 referiram desconhecer este tipo de consulta e 11 não achou importante a sua realização, ressaltando a taxa de não resposta a esta pergunta de 25 por cento. De facto, ainda não podemos esperar, por parte das mulheres, uma 


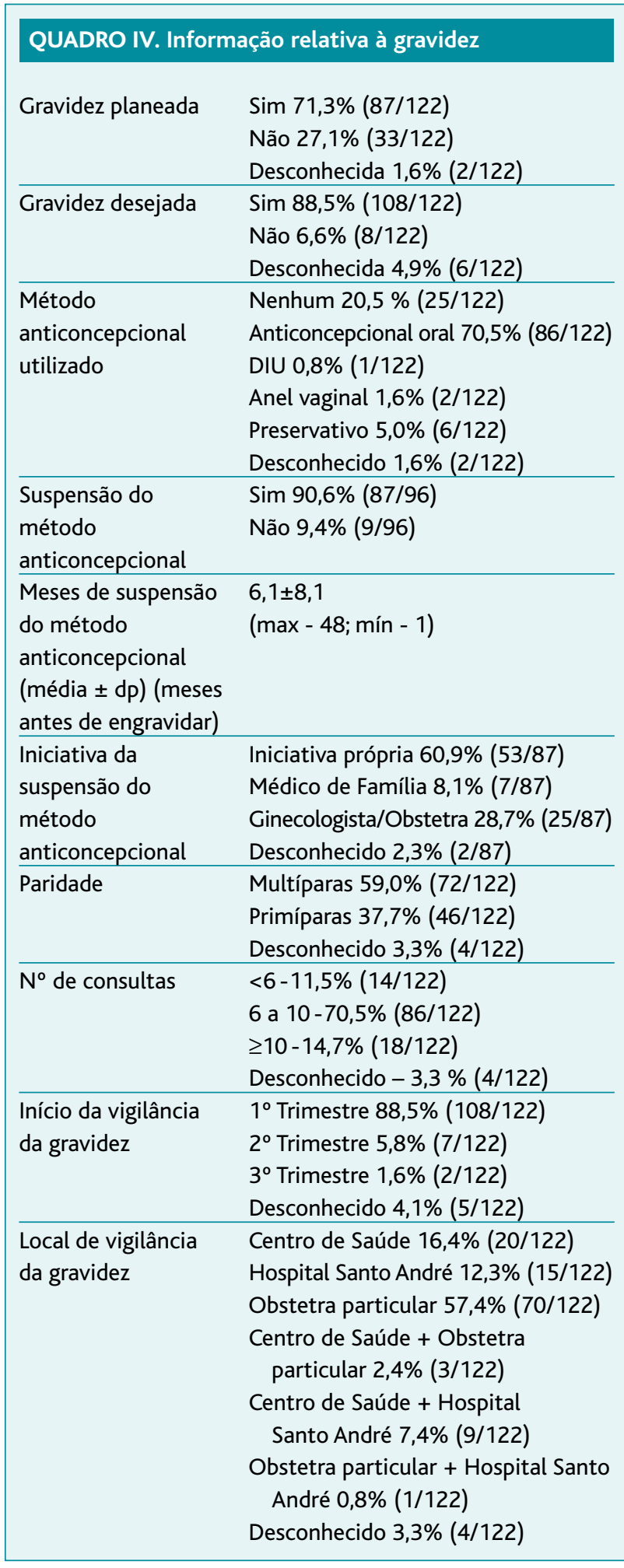

\begin{tabular}{|c|c|}
\hline \multicolumn{2}{|c|}{$\begin{array}{l}\text { QUADRO V. Informação relativa à consulta } \\
\text { pré-concepcional }\end{array}$} \\
\hline $\begin{array}{l}\text { Realização da } \\
\text { consulta } \\
\text { pré-concepcional }\end{array}$ & $\begin{array}{l}\operatorname{Sim} 49,2 \%(60 / 122) \\
\text { Não 49,2\% (60/122) } \\
\text { Desconhecida 1,6\% (2/122) }\end{array}$ \\
\hline $\begin{array}{l}\text { Local da consulta } \\
\text { pré-concepcional }\end{array}$ & $\begin{array}{l}\text { Centro de Saúde } 18,3 \%(11 / 60) \\
\text { Obstetra particular } 75 \%(45 / 60) \\
\text { Centro de Saúde + Obstetra } \\
\text { particular } 5,0 \%(3 / 60) \\
\text { Obstetra particular + Hospital Santo } \\
\text { André } 1,7 \%(1 / 60)\end{array}$ \\
\hline $\begin{array}{l}\text { Razões da não } \\
\text { realização da } \\
\text { consulta } \\
\text { pré-concepcional }\end{array}$ & $\begin{array}{l}\text { Desconhecimento das consultas } \\
18,3 \%(11 / 60) \\
\text { Não achou importante } 18,3 \% \\
\quad(11 / 60) \\
\text { Não teve vaga } 3,4 \%(2 / 60) \\
\text { Gravidez não planeada } 30,0 \% \\
\quad(18 / 60) \\
\text { Outra razão } 5,0 \%(3 / 60) \\
\text { Não responde } 25 \%(15 / 60)\end{array}$ \\
\hline
\end{tabular}

procura espontânea deste tipo de consulta, pelo que é importante divulgarmos e motivarmos as mulheres, desde cedo, para a sua importância.

Em relação ao cumprimento dos protocolos da consulta pré-concepcional, e talvez até surpreendentemente, o critério menos cumprido foi o da suplementação com ácido fólico, juntamente com o aconselhamento sobre exercício físico. Por outro lado, a única relação que se verificou ser estatisticamente significativa entre o local de realização da consulta pré-concepcional e o cumprimento destes protocolos foi para a suplementação com ácido fólico, denotando, ainda, um grande esquecimento, sobretudo por parte dos Médicos de Família. Não é compreensível que a 18 mulheres não tenha sido prescrito ácido fólico. De igual modo, não nos pareceu aceitável que a duas mulheres não tenham sido pedidas análises, a 11 não tenha sido verificado o estado vacinal, a 17 não foi feito o aconselhamento alimentar, a 19 sobre exercício físico, a nove sobre tabaco, a 10 sobre álcool, a 13 sobre drogas, a 10 sobre medicação e a cinco não foi efectuada citologia cervicovaginal. Pareceu-nos particularmente grave, se pensarmos que o não cumprimento destes protocolos 


\begin{tabular}{|c|c|c|c|c|c|c|c|}
\hline \multicolumn{8}{|c|}{$\begin{array}{l}\text { QUADRO VI. Relação entre o } \\
\text { pré-concepcional (teste } \chi^{2} \text { ) }\end{array}$} \\
\hline & & \multicolumn{4}{|c|}{ Local de realização da consulta pré-concepcional } & \multirow[b]{2}{*}{ Total } & \multirow[b]{2}{*}{$P$} \\
\hline & & $\begin{array}{l}\text { Centro de } \\
\text { Saúde }\end{array}$ & $\begin{array}{l}\text { Obstetra } \\
\text { particular }\end{array}$ & $\begin{array}{c}\text { Centro } \\
\text { de Saúde } \\
\text { + Obstetra } \\
\text { particular }\end{array}$ & $\begin{array}{c}\text { Obstetra } \\
\text { particular } \\
+ \text { Hospital de } \\
\text { Santo André }\end{array}$ & & \\
\hline \multirow[t]{2}{*}{ Pedido de análises } & Sim & 11 & 43 & 3 & 1 & 58 & 0,876 \\
\hline & Não & 0 & 2 & 0 & 0 & 2 & NS \\
\hline \multirow{2}{*}{$\begin{array}{l}\text { Perificação estado } \\
\text { vacinal }\end{array}$} & Sim & 11 & 34 & 3 & 1 & 49 & 0,213 \\
\hline & Não & 0 & 11 & 0 & 0 & 11 & NS \\
\hline \multirow{3}{*}{$\begin{array}{l}\text { Aconselhamento } \\
\text { alimentar }\end{array}$} & Sim & 9 & 29 & 2 & 1 & 41 & 0,916 \\
\hline & Não & 2 & 14 & 1 & 0 & 17 & NS \\
\hline & Desconhecido & 0 & 2 & 0 & 0 & 2 & \\
\hline \multirow{3}{*}{$\begin{array}{l}\text { Aconselhamento sobre } \\
\text { exercício físico }\end{array}$} & Sim & 9 & 26 & 2 & 0 & 37 & 0,519 \\
\hline & Não & 2 & 15 & 1 & 1 & 19 & NS \\
\hline & Desconhecido & 0 & 4 & 0 & 0 & 4 & \\
\hline \multirow{3}{*}{$\begin{array}{l}\text { Aconselhamento sobre } \\
\text { tabaco }\end{array}$} & Sim & 11 & 33 & 3 & 1 & 48 & 0,544 \\
\hline & Não & 0 & 9 & 0 & 0 & 9 & NS \\
\hline & Desconhecido & 0 & 3 & 0 & 0 & 3 & \\
\hline \multirow{3}{*}{$\begin{array}{l}\text { Aconselhamento sobre } \\
\text { álcool }\end{array}$} & Sim & 11 & 32 & 3 & 1 & 47 & 0,478 \\
\hline & Não & 0 & 10 & 0 & 0 & 10 & NS \\
\hline & Desconhecido & 0 & 3 & 0 & 0 & 3 & \\
\hline \multirow{3}{*}{$\begin{array}{l}\text { Aconselhamento sobre } \\
\text { drogas }\end{array}$} & Sim & 9 & 30 & 3 & 1 & 43 & 0,768 \\
\hline & Não & 1 & 12 & 0 & 0 & 13 & NS \\
\hline & Desconhecido & 1 & 3 & 0 & 0 & 4 & \\
\hline \multirow{3}{*}{$\begin{array}{l}\text { Aconselhamento sobre } \\
\text { medicamentos }\end{array}$} & Sim & 9 & 35 & 2 & 1 & 47 & 0,391 \\
\hline & Não & 2 & 8 & 0 & 0 & 10 & NS \\
\hline & Desconhecido & 0 & 2 & 1 & 0 & 3 & \\
\hline \multirow{3}{*}{$\begin{array}{l}\text { Realização de citologia } \\
\text { cervicovaginal }\end{array}$} & Sim & 9 & 39 & 2 & 1 & 51 & 0,430 \\
\hline & Não & 2 & 3 & 0 & 0 & 5 & NS \\
\hline & Desconhecido & 0 & 3 & 1 & 0 & 4 & \\
\hline \multirow{3}{*}{$\begin{array}{l}\text { Suplementação com } \\
\text { ácido fólico }\end{array}$} & Sim & 2 & 32 & 2 & 1 & 37 & 0,003 \\
\hline & Não & 9 & 9 & 0 & 0 & 18 & \\
\hline & Desconhecido & 0 & 4 & 1 & 0 & 5 & \\
\hline
\end{tabular}

NS - sem significado estatístico

poderá ter conduzido à manutenção de comportamentos perigosos ou de riscos evitáveis, quer para a mãe, quer para o feto. Efectivamente, temos ainda um grande caminho a percorrer no que diz respeito à consulta pré-concepcional, tendo em vista a redução da morbimortalidade materna e fetal.

Verificou-se haver uma relação estatisticamente significativa entre a realização da consulta pré-concepcional e o nível de escolaridade, estado civil e profissão. As- sim, as mulheres casadas parecem aderir mais a este tipo de consulta, o mesmo se verificando à medida que aumenta o nível de escolaridade e o grau de Graffar, para a classificação da profissão. Por outro lado, não se verificou existir uma relação estatisticamente significativa entre a realização da consulta pré-concepcional e o grupo etário e concelho de residência.

Temos que ter em conta que a grande limitação deste estudo foi a dimensão e a forma de selecção da amos- 


\begin{tabular}{|c|c|c|c|c|c|c|}
\hline & & \multicolumn{3}{|c|}{ Realização de consulta pré-concepcional } & \multirow[b]{2}{*}{ Total } & \multirow[b]{2}{*}{$P$} \\
\hline & & Desconhecido & Sim & Não & & \\
\hline \multirow[t]{6}{*}{ Grupo etário } & 15 aos 19 anos & 0 & 0 & 2 & 2 & 0,233 \\
\hline & 20 aos 24 anos & 1 & 5 & 13 & 19 & NS \\
\hline & 25 aos 29 anos & 1 & 13 & 14 & 28 & \\
\hline & 30 aos 34 anos & 0 & 29 & 26 & 55 & \\
\hline & 35 aos 39 anos & 0 & 9 & 3 & 12 & \\
\hline & 40 aos 44 anos & 0 & 4 & 2 & 6 & \\
\hline \multirow[t]{4}{*}{ Estado civil } & Casada & 1 & 49 & 31 & 81 & 0,001 \\
\hline & Solteira & 0 & 2 & 19 & 21 & \\
\hline & Divorciada & 0 & 2 & 4 & 6 & \\
\hline & Outro & 1 & 7 & 6 & 14 & \\
\hline \multirow[t]{4}{*}{ Escolaridade } & Analfabeta & 0 & 0 & 2 & 2 & 0,001 \\
\hline & Ensino básico & 2 & 7 & 15 & 24 & \\
\hline & Ensino secundário & 0 & 32 & 37 & 69 & \\
\hline & $\begin{array}{l}\text { Ensino superior } \\
\text { /Universitário }\end{array}$ & 0 & 21 & 6 & 27 & \\
\hline \multirow[t]{12}{*}{ Concelho de residência } & Leiria & 2 & 24 & 24 & 50 & 0,583 \\
\hline & Alcobaça & 0 & 4 & 1 & 5 & NS \\
\hline & Batalha & 0 & 3 & 2 & 5 & \\
\hline & Marinha Grande & 0 & 8 & 7 & 15 & \\
\hline & Pombal & 0 & 1 & 2 & 3 & \\
\hline & Ourém & 0 & 3 & 7 & 10 & \\
\hline & Porto de Mós & 0 & 5 & 4 & 9 & \\
\hline & Torres Novas & 0 & 5 & 4 & 9 & \\
\hline & Entroncamento & 0 & 0 & 3 & 3 & \\
\hline & Alcanena & 0 & 6 & 1 & 7 & \\
\hline & Figueira da Foz & 0 & 1 & 0 & 1 & \\
\hline & Desconhecido & 0 & 0 & 5 & 5 & \\
\hline \multirow{6}{*}{$\begin{array}{l}\text { Profissão } \\
\text { (classificação Graffar) }\end{array}$} & $1^{\circ}$ grau & 0 & 11 & 1 & 12 & 0,004 \\
\hline & $2^{\circ}$ grau & 0 & 5 & 4 & 9 & \\
\hline & $3^{\circ}$ grau & 0 & 17 & 15 & 32 & \\
\hline & $4^{\circ}$ grau & 0 & 19 & 19 & 38 & \\
\hline & $5^{\circ}$ grau & 1 & 2 & 3 & 6 & \\
\hline & $\begin{array}{l}\text { Não aplicável/ } \\
\text { Desconhecido }\end{array}$ & 1 & 6 & 18 & 25 & \\
\hline
\end{tabular}

NS - sem significado estatístico

tra, dado o questionário ter sido apenas aplicado no mês de Dezembro. Outro dos pontos fracos deste estudo prende-se com o facto de todas as variáveis dizerem respeito a uma percepção da puérpera do que foi efectuado, não sendo baseadas na verificação escrita de qualquer documento, o que poderá condicionar alguns viéses. Por outro lado, temos que considerar a grande envolvência neste processo das puérperas e a sua colaboração para a execução deste trabalho.

Perante os resultados deste estudo, conclui-se que é fundamental a divulgação e a motivação das mulheres em idade fértil para este tipo de consulta. Os Médicos 
de Família ocupam um lugar privilegiado para a implementação destas actividades. Contamos com inúmeras oportunidades para a informar/educar sobre a parentalidade, a gravidez e o parto: consultas de rotina, consultas de saúde infantil e saúde escolar (sobretudo as consultas dos 15-18 anos do Programa-Tipo em Saúde Infantil e Juvenil), exames pré-matrimoniais, pedidos de Testes Imunológicos de Gravidez (especialmente quando negativos) e, em particular, nas consultas de Planeamento Familiar. ${ }^{6}$

Dado a bibliografia encontrada ter sido limitada, no que respeita a estudos semelhantes, torna-se difícil a discussão do presente trabalho, nomeadamente quanto à comparação de resultados. No entanto, e dadas as limitações do estudo, já anteriormente referidas, parece-nos pertinente a realização de um estudo mais abrangente, dirigido a todas as puérperas de um ano civil, de forma a obtermos uma amostra mais representativa, nomeadamente abrangendo todos os meses do referido ano.

\section{REFERÊNCIAS BIBLIOGRÁFICAS}

1. Frey KA Files JA. Preconception healthcare: what women know and believe. Matern Child Health J 2006 Sep; 10 (5 Suppl): S73-7.

2. DeWeerd S, van der Bij AK, Cikot RJ, Braspenning JC, Braat DD, Steegers
EA. Preconception care: a screening tool for health assessment and risk detection. Prev Med 2002 May; 34 (5): 505-11.

3. Konchak P. Preconception care: "VITAL MOM" - a guide for the primary care provider. J Am Osteopath Assoc 2001 Feb; 101 (2 Suppl): S1-9.

4. Heyes T, Long S, Mathers N. Preconception care: practice and beliefs of primary care workers. Fam Pract 2004 Feb; 21 (1): 22-7.

5. Johnson K, Posner SF, Biermann J, Cordero JF, Atrash Hk, Parker CS, et al. Recommendations to improve preconception health and health care - United States: a report of the CDC/ATSDR Preconception Care Work Group and the Select Panel on Preconception Care. MMWR Recomm Rep 2006 Apr 21; 55 (RR-6): 1-23.

6. Direcção-Geral da Saúde: Prestação de cuidados pré-concepcionais. Circular Normativa No 02/DSMIA, de 16/01/06.

7. Maier KM, Kirkham CM, Lim E, Cheung KW, Grzybowski S. Pregnancy Planning Guide: evidence-based information for prospective parents. Can Fam Physician 2002 Jul; 48: 1199-205.

8. Brundage SC. Preconception health care. Am Fam Physician 2002 Jun $15 ; 65$ (12): 2507-14.

9. Lu MC. Recommendations for preconception care. Am Fam Physician 2007 Aug 1; 76 (3): 397-400.

\section{ENDEREÇO PARA CORRESPONDÊNCIA}

Teresa Maria Bacelo

Avenida do Conde, 5921

4465-097 S. Mamede Infesta

Tlm: 936391736

Recebido em 03/07/2008

Aceite para publicação em 27/02/2009

\begin{abstract}
Introduction: In recent years, growing emphasis has been given to preconceptional care, aiming the identification and modification of the risks that can modify the normal evolution of a future gestation.

Aims: Characterize post-partum women of Hospital de Santo André aiming socio-demographic aspects, life styles and pregnancy; identify women that had preconceptional consultation and characterize the preconceptional consultation.

Methodology: Type of study - descriptive and observacional study; Local - Obstetrics Service of Hospital de Santo André - Leiria; Population studied- Post-partum women admitted during December 2007 in Obstetrics of Hospital de Santo André - Leiria; Methods - an anonymous pre-tested questionnaire has been apllied, regarding socio-demographic characterization, pregnancy, delivery, life styles and preconceptional consultation. Illiterate women, those who didn't know how to read or speak Portuguese and those who didn't accept to participate were excluded. Preconceptional consultation was defined as any consultation which occurred before pregnancy, with the purpose of knowing if everything was going well with women.

Results: 122 women were studied. The predominant age group ranged 30 to 34 years old. The prevalence of women who had preconceptional consultation was of $49.2 \%, 75 \%$ of those $(45 / 60)$ had consultation in a private Obstetrician and only $18.3 \%$ $(11 / 60)$ in a General Practitioner. The main reasons referred for the non-existance of this type of consultation had been an unplanned pregnancy (18/60), not knowing this type of consultation (11/60) and the lack of importance attributed to this type of consultation (11/60).

Conclusion: It is of vital importance the promotion and motivation of women for this type of consultation, and we, as general practitioners, have innumerable chances to make it.
\end{abstract}

Keywords: Preconceptional Consultation; Preconceptional Counselling; Preconceptional Care. 


\section{ANEXO \\ INQUÉRITO}

Por favor leia atentamente as questões e assinale ou escreva a sua resposta no local apropriado. Procure responder a todas as questões. As suas respostas serão tratadas na máxima confidencialidade. Entregue este questionário completamente preenchido antes de ter alta.

I. CARACTERIZAÇÃO DA MÃE

1. Idade anos

2. Raça

1. Caucasiana (= branca)

2. Negra

3. Outra-Qual?

3. Estado civil

1. Casada

2. Solteira

3. Viúva

4. Divorciada

5. Outro-Qual?

4. Escolaridade

1. Analfabeta

2. Ensino básico

3. Ensino secundário

4. Ensino superior / Universitário

5. Situação laboral

1. Trabalhadora

2. Desempregada

3. Estudante

6. Profissão

\section{Concelho de residência}

8. Quantas vezes já esteve grávida?

1. Uma

2. Duas

3. Três

4. Quatro ou mais

9. Utilizava algum método para não engravidar?

1. Sim - Qual?

2. Não

10. Suspendeu o método contraceptivo antes de engravidar?

1. Sim - Quanto tempo antes de engravidar? meses

Por indicação de quem?

1. Iniciativa própria

2. Médico de Família

3. Ginecologista

4. Outro-Quem?

2. Não

II. CONSULTA PRÉ-CONCEPCIONAL

1. Teve alguma consulta antes de engravidar, para saber se estava tudo bem consigo?

1. Sim

2. Não (passe para a pergunta II.3)

\section{Se sim:}

1.1. Onde teve lugar essa consulta?

1. Centro de Saúde

2. Hospital de Santo André - Leiria

3. Ginecologista Particular

4. Outro - onde? 
1.2.0 que foi efectuado? (Assinale a sua resposta em todas as alíneas)

\begin{tabular}{|l|c|c|}
\hline Procedimento & Sim & Não \\
\hline 1. Análises & $\square$ & $\square$ \\
\hline 2. Verificação das vacinas & $\square$ & $\square$ \\
\hline 3. Conselhos sobre alimentação & $\square$ & $\square$ \\
\hline 4. Conselhos sobre exercício físico & $\square$ & $\square$ \\
\hline 5. Conselhos sobre tabaco & $\square$ & $\square$ \\
\hline 6. Conselhos sobre álcool & $\square$ & $\square$ \\
\hline 7. Conselhos sobre drogas & $\square$ & $\square$ \\
\hline 8. Conselhos sobre medicamentos & $\square$ & $\square$ \\
\hline 9. Citologia cervico-vaginal (Papanicolau) & $\square$ & \\
\hline 10. Suplementação com ácido fólico (Folicil $\odot$ ) & $\begin{array}{c}\text { Se sim, quantos meses antes } \\
\text { de engravidar? }\end{array}$ & \\
\hline
\end{tabular}

1.3. Se não: (Responda apenas se não teve consulta pré-concepcional. Se teve passe directamente para as questões do grupo III. Gravidez actual) Porque razão? (pode optar por mais do que uma resposta)

1. Desconhecia essas consultas

2. Não achei importante

3. Não tive vaga

4. Outra razão - Qual?

1.4. Neste momento, e após ter conhecimento destas consultas, acha importante a sua existência?

1. Sim

2. Não

1.5. Numa próxima gravidez procuraria recorrer a uma consulta pré-concepcional?

1. $\operatorname{Sim}$

2. Não

\section{GRAVIDEZ ACTUAL}

1. Esta gravidez foi:

1. Planeada

2. Não Planeada

2. Esta gravidez foi:

1. Desejada

2. Não Desejada

3. Onde foi seguida durante a gravidez?

1. Centro de Saúde

2. Hospital de Santo André - Leiria
3. Ginecologista Particular

4. Outro

4. Quando teve a $1^{\text {a }}$ consulta durante a gravidez?

1. $1^{\circ}$ trimestre da gravidez

2. $2^{\circ}$ trimestre da gravidez

3. $3^{\circ}$ trimestre da gravidez

5. Quantas consultas teve durante a gravidez?

1. Menos de $6(<6)$

2. Entre 6 e $10(\geq 6$ e $<10)$

3. 10 ou mais $(\geq 10)$

IV. HÁBITOS

1. É fumadora?

1. $\operatorname{Sim}$

1.1.1. $\mathrm{N}^{\circ}$ de cigarros/dia antes da gravidez

1.1.2. $\mathrm{N}^{\circ}$ de cigarros/dia durante a gravidez

2. Não

2. Consome bebidas alcoólicas regularmente?

1. $\operatorname{Sim}$

1.1.1. $\mathrm{N}^{\circ}$ de bebidas/semana antes da gravidez beb/dia

1.1.2. $\mathrm{N}^{\circ}$ de bebidas/semana durante a gravidez beb/dia

2. Não

3. Já consumiu drogas ilícitas?

1. Sim

2. Não cig/dia cig/dia 